\title{
Evaluating receiver contributions to acoustic positional telemetry: a case study on Atlantic cod around wind turbines in the North Sea
}

Inge van der Knaap ${ }^{1,2^{*}} \mathbb{D}$, Hans Slabbekoorn², Hendrik V. Winter ${ }^{3}$, Tom Moens $^{1}$ and Jan Reubens ${ }^{4}$

\begin{abstract}
Background: The effect of individual acoustic receiver contributions to animal positioning is a crucial aspect for the correct interpretation of acoustic positional telemetry (APT). Here, we evaluated the contribution of each receiver within two APT designs to the number of tag signals detected and the position accuracy of free-ranging Atlantic cod, through data exclusion of single receivers from the analysis. The two APTs were deployed around offshore (ca $50 \mathrm{~km}$ ) wind turbines at which 27 individual cod were tagged.

Results: We found that the exclusion of data from an APT receiver that was positioned within the movement area of the individual fish reduced the number of tag signals detected and the position accuracy of the set-up the most. Excluding the data from a single receiver caused a maximum of 34\% positions lost per fish and a maximum increase in core area of $97.8 \%$. Single-receiver data exclusion also caused a potentially large bias in the reconstruction of swimming tracks. By contrast, exclusion of a receiver that was deployed within $50 \mathrm{~m}$ from a turbine actually improved fish position accuracy, probably because the turbine can cause signal interference as a reflective barrier.

Conclusions: We recommend that an exploratory small-scale study like the one presented here be conducted before embarking on a larger-scale APT study. By excluding the data of single receivers from the positioning analysis, we were able to explore the suitability of a receiver set-up for the movement patterns of our target species. Furthermore, when a receiver is lost from an APT during deployment, the data should be treated with care as our results show that changes in triangulation outcome can lead to considerable differences in swimming tracks and home range estimates.
\end{abstract}

Keywords: Acoustic telemetry, Position triangulation, Behaviour, Atlantic cod, Offshore structures, Wind power

\section{Background}

Acoustic positional telemetry (APT) is an established method to study fine-scale fish behaviour and movement at large spatial and temporal scales $[1,2]$. In an open marine environment, the acoustic receivers that form an $\mathrm{APT}$ are often placed in regular squared and triangular grids [3] or in a circular constellation [4,5], depending on

${ }^{*}$ Correspondence: iej.vanderknaap@gmail.com

${ }^{1}$ Marine Biology Lab, Ghent University, Krijgslaan 281, 9000 Ghent, Belgium

Full list of author information is available at the end of the article the location and research questions [6] and on the species-specific behaviour of the target animals. Some fish species exhibit a high residency and site fidelity, while others are more mobile [7]. Even within species, movement patterns may vary with life stage, personality traits and subpopulations $[8,9]$. The spatial deployment of receivers therefore influences the outcome and reliability of any APT study.

In addition, the performance of a receiver set-up in a marine open-water system will be affected by local habitat conditions [10] and by the dynamic nature of environmental factors $[11,12]$. The difference in time of arrival 
of the transmitter signals at various hydrophones is used in the positioning algorithm. Any factor influencing the speed of sound and signal propagation in the water will therefore affect APT performance [13, 14]. Habitat-specific features (e.g., vegetation type and density, bottom characteristics, the presence of rocks and man-made obstacles) can block signal propagation [15]. Furthermore, natural events such as currents and surface waves can influence receiver detection range $[12,16]$ and lead to signal interference through receivers getting temporarily buried or even lost [17]. If this occurs, an APT setup may suffer significantly in terms of the number of tag signals detected and position accuracy. The impact of losing a receiver in an APT study is usually unknown, since information stored on the receiver is no longer available. Furthermore, trade-offs exist between detection range (i.e. area covered by receivers that are able to detect animals) and costs, as acoustic telemetry studies are very expensive [6]. Before embarking on a large-scale study, exploring the effects of excluding the data from a receiver on the overall results can greatly facilitate the design of a cost-efficient ATP set-up and enhance understanding of the consequences of receiver loss.

Atlantic cod (Gadus morhua) at offshore wind farms in the North Sea are a suitable model system to explore the contribution of individual receivers in an APT design. During summer, cod spend several months residing close to a turbine's scour bed, which provides food and shelter [18-20]. They generally have a small home range around a single wind turbine [17], but occasionally make excursions to an adjacent one [21]. Later in the season, cod move away from these offshore structures towards coastal areas for spawning [22, 23]. Additionally, fishing or shipping is not allowed in the wind farms in the Belgian Part of the North Sea (BPNS). This limits the risk of losing tagged fish or receivers to bottom-trawl fisheries compared to other wind farms in neighbouring countries. There are no data yet confirming receiver network suitability for high-resolution spatial tracking of individual fish around a wind turbine, nor is there any exploration reported on the impact of losing or removing a receiver from an operational network.

We evaluated the contributions of individual receivers to the detection rate and position accuracy within two acoustic positional telemetry (APT) designs for Atlantic cod at a wind farm in the BPNS. We aimed to answer the following questions: do individual receivers contribute equally to the spatial data collection and position accuracy? Which local factors explain variation among individual receivers? To what extent is the reconstruction of fish swimming tracks affected by data exclusion from individual receivers? We addressed these questions by quantifying the effects of simulated data exclusion of single receivers on cod detection and positioning data. Our study results provide insights into how positional array designs can be improved for studies into the spatial behaviour and activity changes of fish in response to disturbance by anthropogenic noise (e.g., pile driving, seismic surveys) and reveal the consequences of removing or losing a receiver.

\section{Methods \\ Study site}

This study was performed in the offshore wind farm Belwind $\left(51.670^{\circ} \mathrm{N} 2.802^{\circ} \mathrm{E}\right)$, situated on a sand bank ca 50 $\mathrm{km}$ off the Belgian coast (Fig. 1a) [24]. The 55 turbines (Fig. 1b) in the wind farm have steel monopile foundations, surrounded by a scour bed protection layer consisting of stones of various sizes (information obtained from Van Oord Dredging \& Marine Contractors). The monopile turbines and the scour beds have a diameter of $5 \mathrm{~m}$ and of $\sim 40 \mathrm{~m}$, respectively; the precise extent of the scour bed varies, but covers approximately $500 \mathrm{~m}^{2}$ per monopile [25]. The seabed between turbine scour beds predominantly consists of medium-grained sand dunes, which are formed by the tidal currents. The water depth at the study site was between 20 and $30 \mathrm{~m}$ during our study, including tidal fluctuations [24].

\section{Experimental design}

VR2AR (Innovasea, Halifax, N.S. Canada) acoustic receivers were used. Two APT designs were deployed from July 4th until September 28th 2017 around two wind turbines: the northern F05 and the more centrally located C05 turbine (Figs. 2a, 3a). The set-up around turbine F05 included eight receivers, six of which were placed in a circular shape with similar spacing $(150 \mathrm{~m}$ on average), the remaining two inner receivers being positioned at approximately $50 \mathrm{~m}$ from the edge of the turbine base (Fig. 2a). At turbine C05, ten receivers were placed in a triangular-grid configuration, with $150 \mathrm{~m}$ up to $200 \mathrm{~m}$ spacing between adjacent receivers (Fig. 3a). Detection probability at these distances has been tested in the same environment and under similar environmental conditions [12], and remained above 70\%, even during harsh environmental conditions. During the deployment period, receiver C05-8 was accidentally lost on the 21st of September. All other 17 receivers remained functional for the entire deployment period. They were bottom-moored using a mooring weight of $60-\mathrm{kg}$ natural stone and a buoy keeping the receiver upright approximately $1.5 \mathrm{~m}$ above the seabed [12].

We caught and tagged 27 Atlantic cod (total length range $33-43 \mathrm{~cm}$ ) with V13AP transmitters (Innovasea, Halifax, N.S. Canada) between July 4th and September 1st 2017 (Table 1). Fish were caught using hook and line 


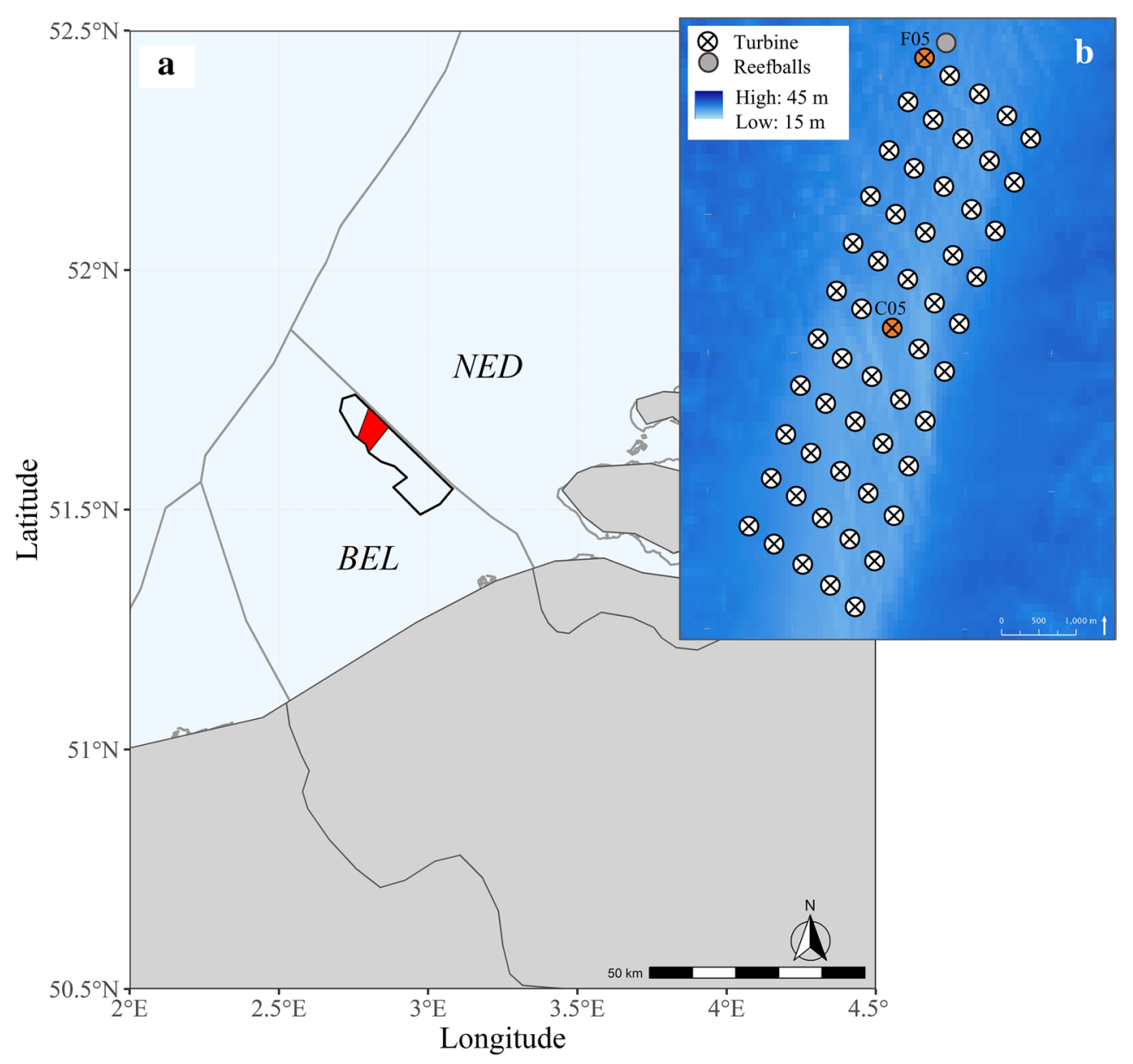

Fig. 1 Location of Belwind wind farm in the Belgian part of the North Sea. a Grey lines outline the country's land and water borders (e.g., EEZs). Contours of the offshore area designated to wind farm construction are shown in black, while red indicates the location of the Belwind park. $\mathbf{b}$ Overview of monopile turbine positions at Belwind. The two orange turbines are the ones around which APT's were deployed. Depth around the turbines varied between 20 and 30 m [bathymetry data obtained from "European Marine Observation and Data Network" (EMODNet)]

from up to $30 \mathrm{~m}$ depth and slowly reeled in to prevent barotrauma. Individuals were kept in a holding tank for observation. If fish displayed any sign of serious discomfort or abnormal behaviour (e.g., being unable to keep buoyancy or swimming at the surface), they were not used for tagging. Fish were sedated using clove oil $(0.03 \mathrm{ml} / \mathrm{l})$. Upon losing equilibrium, they were placed on their back in a holder at a slight angle, keeping mouth and gills submerged in oxygenated seawater. An incision $(2-3 \mathrm{~cm})$ was made on the ventral side through which the acoustic tag was slid into the abdominal cavity. The incision was closed using three monofilament sutures. Fish were measured and tagged with an additional T-bar Floy tag in front of the dorsal fin to avoid double tagging in case individuals would be recaptured (which did not happen). The tagging procedure took on average $5 \mathrm{~min}$, after which the animal was placed in a recovery tank. Upon resuming normal swimming behaviour, individuals were released at the catch site (i.e. turbine F05 or C05). We tagged fish in two rounds, with two groups of tags set at different transmission intervals (Table 1). A transmitter's interval delay was set for a period of 30 days to a random delay varying between $40-80 \mathrm{~s}$ or $30-60 \mathrm{~s}$ (Table 1 ). We used two different intervals to investigate if these would lead to differences in numbers of detections or positions. We found no such differences and therefore pooled the data from both groups for analyses.

\section{Data analysis}

Data from the receivers were uploaded to the European Tracking Network (ETN) data platform (https://www. lifewatch.be/etn). Per positional set-up, a linear time correction of raw detections was performed (on the online Fathom Position platform, https://position.fathomcent 
ral.com) to correct for differences in internal clock drifts of the different receivers. To calculate transmitter $x-y$ position, we used a hyperbolic positioning algorithm that employed the time-difference of arrival (TDOA) of a coded signal by three or more receivers. This yielded a dataset per APT set-up design (i.e. F05 and C05) containing information on the number of detections per fish and receiver, and triangulated positions with setup-specific position accuracy estimates. The indicator of position triangulation accuracy provided is called the horizontal position error (HPE) [26]. HPE is a dimensionless estimate of position accuracy based on the relationship between theoretical position error sensitivities and observed measurement errors for synchronization tags [26], calibrated to the local environmental conditions (water temperature: $17-19{ }^{\circ} \mathrm{C}$; salinity $33.2 \mathrm{ppt}$ ). HPE is set-up-specific and therefore can only be used to compare positions calculated through multiple receiver combinations within the same set-up $[27,28]$. The lower the HPE, the higher the expected position accuracy.

We excluded all data from the first day after tagging to avoid possible impact of catching and tagging on fish behaviour. We scanned the dataset for stationary tags (i.e. tags remaining stationary for longer periods of time while acceleration remained $0 \mathrm{~ms}^{-2}$ as these would indicate an expelled tag) but found none. No prior position filtering was applied, based on set-up-specific accuracy (e.g., horizontal position error [26]), since the contribution of each individual receiver on fish positions triangulation, is required this the analysis.

We evaluated the contribution of each receiver within the two APT arrays (i.e. eight for the APT at F05 and nine for the APT at C05) to the number of tag signals detected and position accuracy by excluding the data recorded by each receiver once from the position triangulation analysis. For every receiver exclusion, the cod positions with their associated HPE were recalculated (online fathom position platform). Cod were expected to reside close to the turbine and were therefore assumed to be detected by the APT when they were in the detection area. To understand the effect of excluding the data from a single receiver on the APT performance, we assumed that when all data from all receivers within each APT were included in the positional analysis, the number of fish positions detected was $100 \%$ and the triangulated positions were the "base" fish positions. This enabled us to determine two metrics for each APT performance for each single-receiver exclusion (i.e. eight or nine for F05 and $\mathrm{C} 05$, respectively): position accuracy and set-up efficiency $[1,15]$. The latter was calculated as the proportion (\%) of daily successfully calculated positions by the APT [i.e. (number of positions when one receiver is removed/number of positions when all receivers are included) * 100]. Position accuracy was the variability in horizontal position error (HPE) and was the standard deviation of the mean daily HPE associated with all cod positions. A positive difference in HPE indicates a reduced position accuracy, and a negative difference in HPE an improved accuracy in comparison to the complete APT. These metrics were calculated and averaged to give a daily value for both receiver designs per singlereceiver exclusion for all fish (27 fish in total), including all days with at least 100 detections for that fish. All calculations were performed in R Studio (version 4.0.0).

To illustrate the effect of receiver loss, we evaluated the effect of data exclusion from single receivers on shifts in the triangulated positions of fish with a high residency. We identified fish with high residency by calculating their residency index (RI). The RI was defined by dividing the hours an individual fish was detected by the total number of hours between first and last day of detection (maximum of 30 days $=720 \mathrm{~h}$ ). A value of 0 or 1 indicated no residency or permanent residency, respectively $[29,30]$. Four fish (two at turbine F05 and two at turbine C05), that were detected for more than 10 days, exhibited a high RI of $>75 \%$. Horizontal space use patterns (i.e. two-dimensional in metres) of these four resident cod were evaluated using 50\% (core use area) and 95\% (home range extent) kernel utilization distributions (KUDs) [31]. KUDs are a common approach to estimate the activity space of animals from telemetric tracking data [32, 33]. All calculations were performed in $\mathrm{R}$ Studio (version 4.0.0) using R package $k s$ [34].

\section{Results}

\section{Individual receiver contributions to APTs}

Set-up efficiency was based on all derived cod positions: 76,743 at turbine F05 and 31,202 at turbine C05. To evaluate position accuracy, we used a sub-set of position data to include only positions that could be calculated in all single-receiver exclusion options, resulting in 62,240 and 23,916 positions for turbines F05 and C05, respectively.

Excluding the data from receivers from the APT around turbine F05 reduced the mean daily set-up efficiency to $78-93 \%$ of the total detections (Fig. 2c), and position accuracy (change in HPE per position) by 0.06-0.94 HPE on average, depending on the receiver that was excluded (Fig. 2d). Exclusion of receiver F058 , one of the most central receivers with respect to fish spatial area use (Fig. 2b), had the strongest impact on efficiency (Fig. 2c). The daily percentage of derived positions was reduced to $78 \pm 1.8 \%$ (mean $\pm S E$ ) for this receiver (Fig. 2d). Excluding a receiver on the east side of the array (i.e. F05-3 or F05-4) lowered the number of derived positions to $85 \pm 1.4 \%$ and $84 \pm 0.8 \%$, 


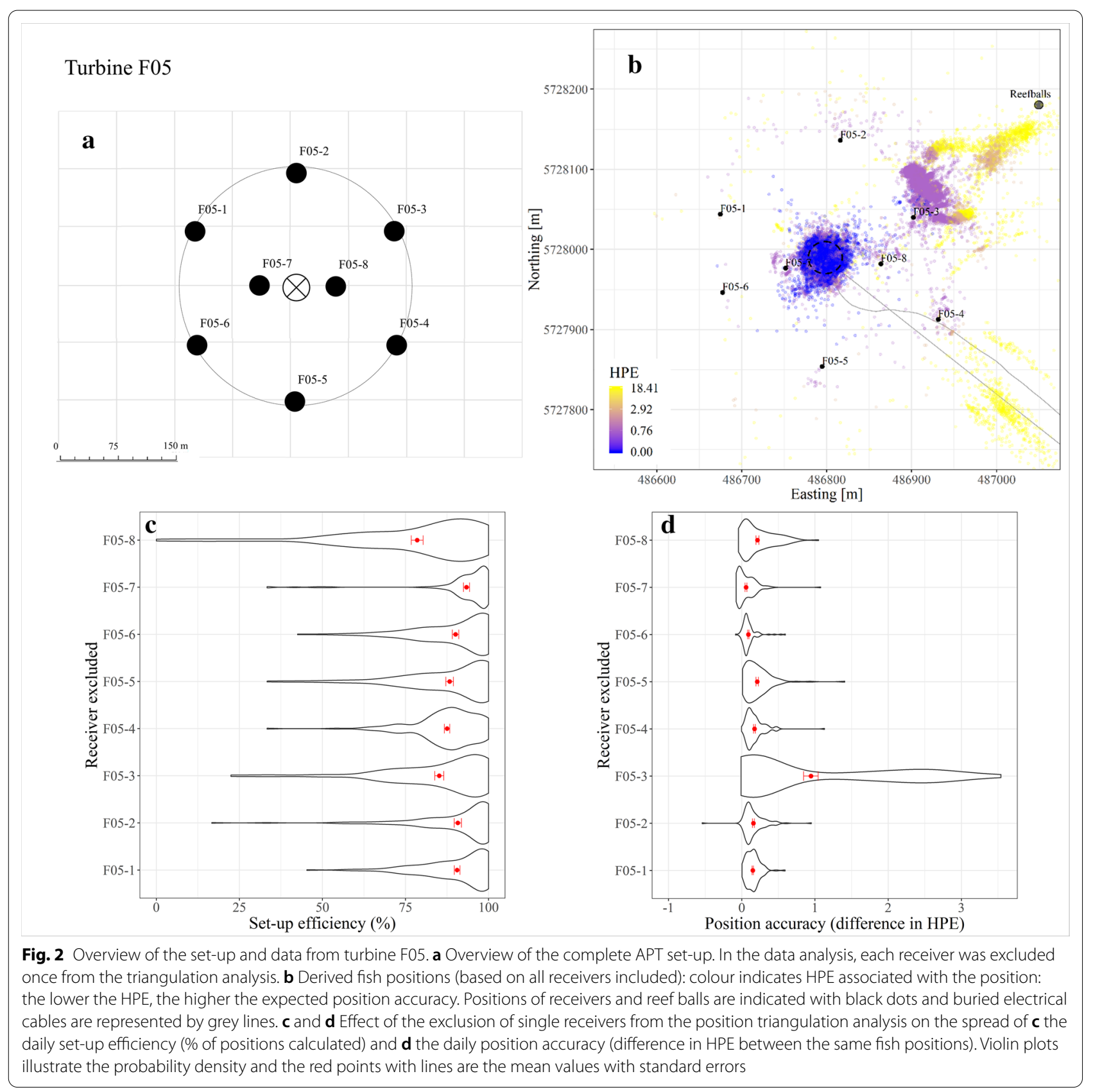

respectively (Fig. 2c). The position accuracy was affected most when excluding receiver F05-3, which increased HPE to $0.94 \pm 0.099$ (mean \pm SE) per position, as this receiver was critical for many positions of fish that moved to and from the nearby reef balls (Fig. 2b). Accuracy improved for 10 and $48 \%$ of the positions when one of the central receivers (i.e. F05-8 or F05-7) was excluded from the analysis (i.e. the HPE difference was negative for these positions, Fig. $2 \mathrm{~d}$ ).
Excluding data from single receivers around the turbine $\mathrm{CO} 5$ reduced the percentage of positions that could be determined to 61-99\% (Fig. 3c) and position accuracy by $0.11-0.44$ HPE (Fig. 3d). Excluding the two central receivers (C05-5 and C05-6) had a pronounced effect on the daily set-up efficiency, lowering the percentage of triangulated positions to $61 \pm 3.7 \%$ (mean \pm SE) or $75 \pm 2.6 \%$, respectively (Fig. 3c). Likewise, excluding receivers on the south side of the turbine (C05-2 or C05-3) contributed significantly to the 


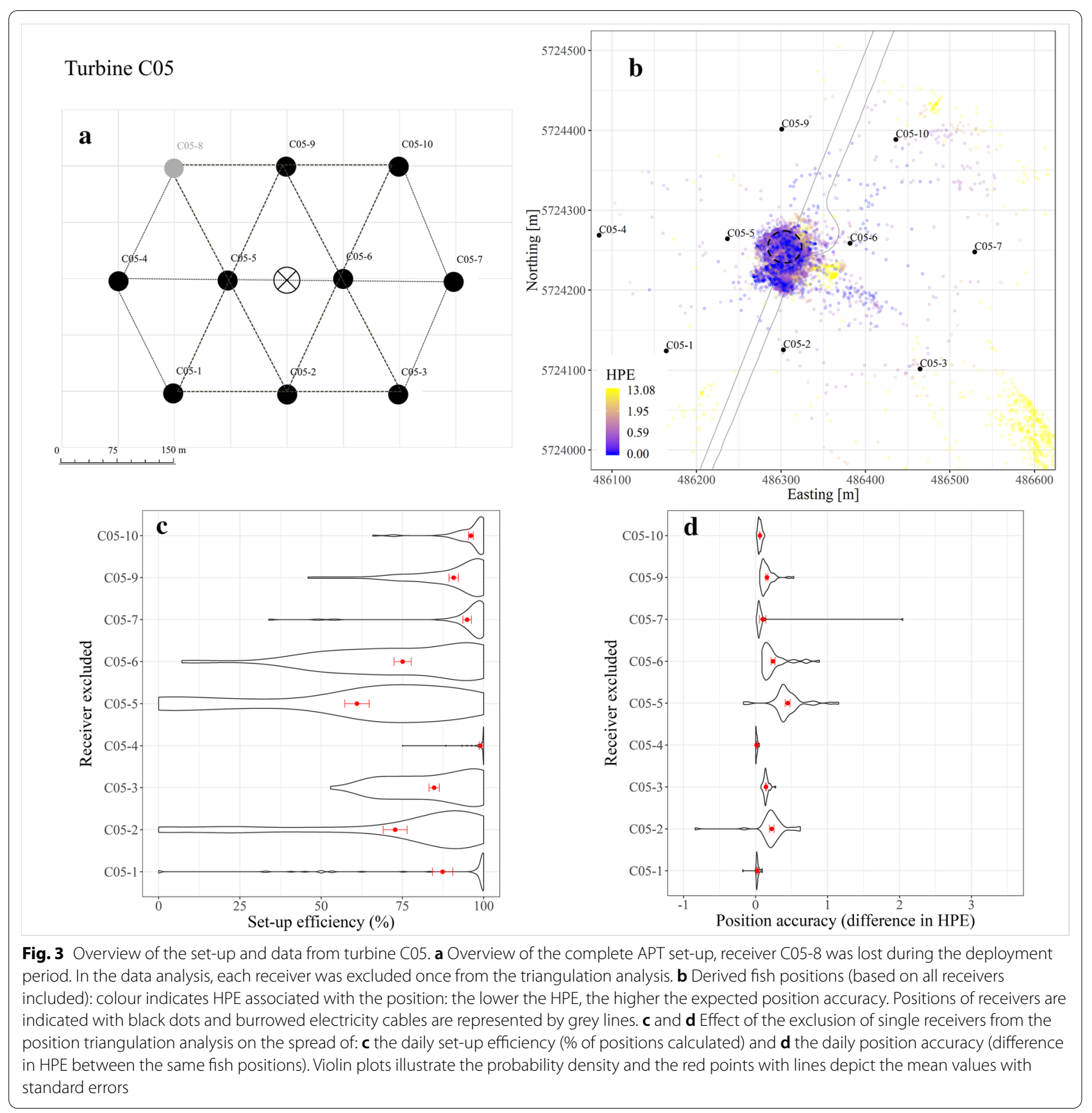

Table 1 Number of cod tagged per turbine and signal transmission delay

\begin{tabular}{llll}
\hline Catch and tag date & Turbine & $\begin{array}{l}\text { Cod tagged } \\
(\#)\end{array}$ & $\begin{array}{l}\text { Random } \\
\text { transmission } \\
\text { interval (s) }\end{array}$ \\
\hline 4-17 July 2017 & F05 & 8 & $40-80$ \\
13 July 2017 & C05 & 6 & $40-80$ \\
23 Aug 2017 & F05 & 5 & $30-60$ \\
1 Sep 2017 & C05 & 8 & $30-60$ \\
\hline
\end{tabular}

set-up efficiency, lowering the percentage of positions to $73 \pm 3.7 \%$ or $85 \pm 1.6 \%$, respectively (Fig. $3 \mathrm{c}$ ). The receiver contribution to position accuracy revealed a similar pattern. When either of the two central receivers (C05-5 or C05-6) was removed, the HPE increased with $0.45 \pm 0.03$ (mean $\pm \mathrm{SE}$ ) or $0.17 \pm 0.06$ (i.e. the accuracy of positions were reduced), respectively (Fig. 3d). This occurred to a lesser extent when the southern C05-2 or northern C05-9 receivers were 
excluded (HPE increased by $0.22 \pm 0.03$ or $0.16 \pm 0.01$, respectively) (Fig. 3d). This reflected the general proximity of fish to the turbine.

\section{Effect of receiver loss on fine-scale fish tracks and KUD}

Our results show that the proportion of the positions of the four fish with a high RI (Table 2) derived from the complete receiver set-up is reduced by a single-receiver loss by $4-14 \%$ and $0-34 \%$ for APTs F05 and C05, respectively. The location of the triangulated position of a given fish showed a large shift when a particular receiver was excluded. For example, core area (i.e. 50\% KUD) of fish 6 changed from 390 to $300-780 \mathrm{~m}^{2}$ depending on which receiver was removed from the APT at turbine F05 (Table 2). Figure 4 uses the same 3-h fish tracks and 50\% KUD to demonstrate the extent to which triangulated fish positions can shift in space with or without the data from a single receiver. Exclusion of some receivers caused a small change in core area, between 2.3 and $22.3 \mathrm{~m}^{2}$ (Table 2), while exclusion of others caused a large change in core area, between 59.6 and $384.8 \mathrm{~m}^{2}$ (Table 2), for the four resident fish (Fig. 4).

\section{Discussion}

Our study revealed considerable variation in individual receiver contributions to position accuracy within two acoustic positional telemetry (APT) designs. Critical factors explaining the variation of both outer-edge and inner-circle receivers were the location of the core area of fish activity, the direction of specific journeys outside the receiver set-up area, and the receiver proximity to the turbine. Receivers that overlapped with the spatial distribution of the tagged cod whose core area was concentrated at the turbine base contributed most to the APT's performance. Consequently, excluding the data from a receiver close to the turbine base reduced the percentage of positions derived the most. This was especially the case when the outer-edge receivers were positioned at a distance of more than $200 \mathrm{~m}$ from the turbine (as was the case for the outer receivers at turbine C05), and less so when this distance was around $150 \mathrm{~m}$ (as was the case for all receivers at turbine F05). Additionally, the presence of the reef balls north-east of turbine F05 led to a high contribution of receiver F05-3 to both set-up efficiency and position accuracy, as exclusion of this receiver from the analysis removed positions detected outside of the APT array (Fig. 2b). Excluding the data of a single receiver from the analysis, furthermore, resulted in variable changes of fish movement-tracks and spatial area use. Again, loss of the receivers closest to the core area with most fish positions had the largest effect on the fish swimming track and home range.

\section{Lessons for an optimal APT design}

The aim of most behavioural APT studies is to understand the movement behaviour of individually tagged animals at a fine scale $[1,2]$. However, the choice for a particular APT design will also influence how often the target animal is detected as well as the accuracy of positions, which might affect the inferred animal movement patterns. Our results showed distinct patterns in position distribution and cod movement between the two APT locations. Cod at turbine C05 constrained their movements mostly around the turbine, while cod at turbine F05 made frequent excursions towards the adjacent reef balls. Cod residing in offshore windfarms are known to occasionally move between turbines [21], and the relative proximity of the reef balls to turbine F05 $(\sim 250 \mathrm{~m})$ most likely resulted in a clear capture of this movement behaviour by the APT. This resulted in very different patterns in position accuracy and receiver contribution between the two APT arrays. When receivers are positioned too far from the animals' core area, they will be less likely to pick up tag signals [11]. Consequently, understanding how a target species will use a spatial area is fundamental to the study outcome and may accordingly require adjustments to juxtaposition of the receivers in the array. This underlines the need for studies similar to ours [c.f. 35] to understand the spatial use of the target species and receiver detection range before undertaking a full-scale project.

Our results furthermore demonstrate that exclusion of either one of the two receivers closest to turbine F05 (i.e. $\approx 50 \mathrm{~m}$ ) improved HPE values for fish positions and thus position accuracy. This was not the case for either of the two receivers closest to $\mathrm{C} 05$, which were positioned further from the turbine $(\approx 150 \mathrm{~m})$. This difference is therefore also likely due to a proximitydependent impact of the monopile on signal propagation. The monopile forms a reflective barrier in the middle of the receiver set-up that can cause tag signal reflections and result in multiple signals from the same tag at a nearby receiver [26]. This phenomenon of signal reflection by barriers (e.g., water surface, air bubbles, sediment or obstacles) is called "Close Proximity Detection Interference" (CPDI) [36, 37]. Consequently, when designing an APT around a reflective barrier, position accuracy can be improved or stabilized by keeping the receivers as distant from the reflective barrier as possible.

Bathymetry can influence sound propagation [38] and therefore affect signal detection and receiver contribution to APT performance. We moored the receivers on a sand bank with dune-like bathymetry (depth may have varied by 1-3 $\mathrm{m}$, EMODNet). The structure and position of these dunes can vary under the influence of 
Table 2 Effect of single-receiver exclusion for four resident cod

\begin{tabular}{|c|c|c|c|c|c|}
\hline Fish with RI > 75\% & Wind turbine & Receiver removed & Positions $(\#)^{\mathrm{a}}$ & KUD 50\% $\left(\mathrm{m}^{2}\right)^{\mathrm{a}}$ & KUD $95 \%\left(\mathrm{~m}^{2}\right)^{\mathrm{a}}$ \\
\hline 6 & F05 & None & 13,908 & 393.3 & 3912.7 \\
\hline 6 & F05 & F05-1 & -579 & +22.3 & -250.8 \\
\hline 6 & F05 & F05-2 & -814 & -95.8 & -1201.2 \\
\hline 6 & F05 & F05-3 & -1559 & +384.8 & +4138.1 \\
\hline 6 & F05 & F05-4 & -813 & +31.2 & -942.2 \\
\hline 6 & F05 & F05-5 & -307 & -67.5 & -464.5 \\
\hline 6 & F05 & F05-6 & -398 & -31.6 & -114.9 \\
\hline 6 & F05 & F05-7 & -321 & +64.1 & -228.7 \\
\hline 6 & F05 & F05-8 & -1862 & -37.7 & -342.5 \\
\hline 18 & F05 & None & 28,601 & 341.5 & 5393.9 \\
\hline 18 & F05 & F05-1 & -1626 & +50.4 & -34.4 \\
\hline 18 & F05 & F05-2 & -816 & -6.2 & -1649.6 \\
\hline 18 & F05 & F05-3 & -572 & +0.7 & -61.1 \\
\hline 18 & F05 & F05-4 & -1271 & +82.1 & -542.3 \\
\hline 18 & F05 & F05-5 & -2306 & +95.7 & -199.3 \\
\hline 18 & F05 & F05-6 & -1638 & +14.2 & -257.1 \\
\hline 18 & F05 & F05-7 & -472 & +56.5 & -618.3 \\
\hline 18 & F05 & F05-8 & -1603 & +10.5 & -960.2 \\
\hline 10 & C05 & None & 16,427 & 194.5 & 1925.2 \\
\hline 10 & C05 & C05-1 & -27 & -9.8 & -39.6 \\
\hline 10 & C05 & C05-2 & -1380 & +59.6 & +528.3 \\
\hline 10 & C05 & C05-3 & -2080 & +30.1 & -189.4 \\
\hline 10 & C05 & C05-4 & -14 & +4.6 & +18.4 \\
\hline 10 & C05 & C05-5 & -1977 & +63 & +583 \\
\hline 10 & C05 & C05-6 & -2143 & -22.2 & -625.2 \\
\hline 10 & C05 & C05-7 & -319 & +19.4 & -513.5 \\
\hline 10 & C05 & C05-9 & -341 & +23.8 & -59.4 \\
\hline 10 & C05 & C05-10 & -163 & -5.7 & -216.9 \\
\hline 27 & C05 & None & 5197 & 336.6 & 2630.3 \\
\hline 27 & C05 & C05-1 & -59 & -8.6 & -116.7 \\
\hline 27 & C05 & C05-2 & -464 & +134.8 & +245.4 \\
\hline 27 & C05 & C05-3 & -500 & +55.7 & +1.3 \\
\hline 27 & $\mathrm{CO5}$ & Co5-4 & -48 & -13 & -126.2 \\
\hline 27 & C05 & C05-5 & -791 & +51.7 & +797.8 \\
\hline 27 & C05 & C05-6 & -724 & -25.3 & -430.7 \\
\hline 27 & C05 & C05-7 & -157 & +2.3 & -255.3 \\
\hline 27 & C05 & C05-9 & -389 & +44 & +228.7 \\
\hline 27 & C05 & C05-10 & -148 & -39 & -325 \\
\hline
\end{tabular}

$R /$ residency index, KUD kernel utilization distribution

a + or - indicates change from no receivers removed

current direction and strength, and can cause acoustic shadow effects of receivers behind these structures by blocking part of a receiver's listening angle. Additionally, currents can affect the angle at which a receiver is standing (i.e. "tilt"), which can also directionally bias the receiver's listening angle. Tilt is one of the main influencers of detection range [12] and, together with water flow noise, can hamper detectability [16]. At our study site, the semi-diurnal flood and ebb currents flow to the north-east and south-west (respectively), with current speeds typically reaching up to $1 \mathrm{~m} / \mathrm{s}$ during the turn of the tide [39]. Change in receiver listening angle could have influenced the spatial distribution of fish positions to be more towards the west side of both turbines (which is likely more sheltered from the current by the turbine), either because of a true spatial preference of the fish or 

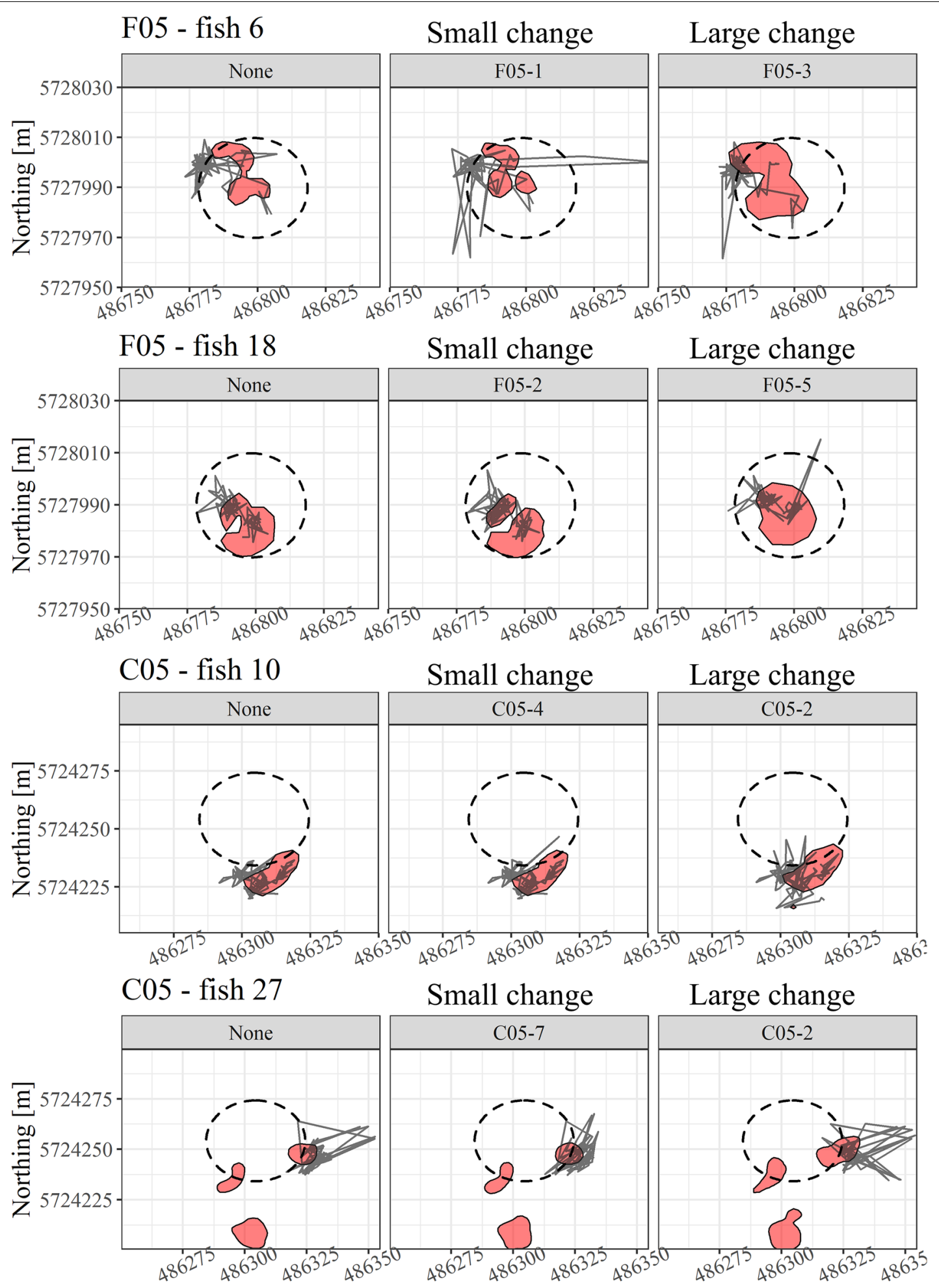

Easting [m]

Fig. 4 The same 3-h tracks (grey lines) and 50\% core kernel utilization distributions (KUD in red) of the four cod with a residency index (RI) $>75 \%$, plotted when all receivers were used for the position triangulation (left column: none) and when a single receiver was excluded (simulated loss) from the analysis, which caused a small change in core area, between 2.3 and $22.3 \mathrm{~m}^{2}$ (middle column), and a large change in fish core area, between 59.6 and $384.8 \mathrm{~m}^{2}$ (right column) 
because of a higher detectability of signals. Obviously, the receiver listening angle in environments with high current speeds can be improved by fixing the receiver in a solid construction above the seabed [40].

\section{Consequences of receiver loss}

We mimicked receiver loss through the exclusion of data from single receivers in the APT array. Receiver loss is unfortunately quite common when receivers are deployed for long periods in offshore areas [17, 41], but also in more shallow coastal areas [41-43, current study]. Our results show that the effect of receiver loss depends on how well an APT is covering the spatial area used by the target species. If the array is larger than the home range of the species, losing one receiver may not have a very large effect on the information recovered. However, considerable shifts in the estimated swimming tracks, or direction of frequent journeys outside the set-up range, can occur if a receiver close to the core area of a tagged animal is lost. Our results provide insights into receiver network design and potential consequences of receiver loss for future studies into the spatial response and activity changes of fish due to human disturbance (e.g., effects of anthropogenic sounds on fish movement $[44,45])$.

\section{Conclusions}

Our results confirmed that a set-up of receivers around a turbine, separated by distances tailored to local propagation conditions (detection range), can provide an APT array suitable for recording the movement and site fidelity of cod resident around wind turbines. We also show that increased resolution of fine-scale positioning can be achieved by placing additional receivers within the array. Locations in close proximity to the turbine should be avoided, however, as this will lower the position accuracy. Based on our findings, we advocate a circular APT design, with an additional receiver in the middle of the array, for future studies on the movement behaviour of fish with a high residency around hard substrates. We also recommend fixing the receiver in a solid construction above the seabed to reduce detection problems due to sand dunes and current-related receiver tilt. Furthermore, our results reveal that the loss of one receiver from an array can result in significant changes in triangulation data, which can lead to considerable shifts in measured swimming tracks and home ranges. Our results also show that a small-scale pilot study allows to test the suitability of a receiver array for the specific movement patterns and local tracking conditions of a particular target species and is recommended before embarking on any larger-scale APT study.

\section{Abbreviations}

BPNS: Belgian part of the North Sea; CPDI: Close proximity detection interference; ETN: European Tracking Network; HMM: Hidden Markov models; HPE: Horizontal positioning error; KUD: Kernel utilization distribution; RI: Residency index; TDOA: Time-difference of arrival; VeDBA: Vector dynamic body acceleration; VPS: Vemco Positioning System.

\section{Acknowledgements \\ J. Hubert, J. Campbell, F. Soudijn, P. Verhelst, J. Goossens, J. Vermaut and T. Versteeg assisted with the set-up of the receivers, data collection and fish cap- ture. We thank J. MacAulay and F. Smith for their help and advice on receiver data analysis and B. Lonneville for her help with the wind farm figure. We acknowledge Parkwind for their kind cooperation and for granting access to the offshore wind farm 'Belwind'. This work was supported by the E\&P Sound and Marine Life Joint Industry Programme (JIP) as part of the 'PCAD4Cod' project. Infrastructure for fieldwork (RV Simon Stevin, RHIB Zeekat and receiver deployment) was provided by the Flanders Marine Institute and funded by the Research Foundation-Flanders (FWO) as part of the Belgian contribution to LifeWatch. This work was further supported by COST Action CA18102. Lastly, we thank all reviewers for their contributions that have greatly improved the paper.}

\section{Authors' contributions}

JR, HS, HW, TM and IvdK conceived the ideas and designed the methodology; JR, HW and IvdK performed the fieldwork and collected the data; IvdK analysed the data; IvdK led the writing of the manuscript. All authors read and approved the final manuscript.

\section{Funding}

Funding for this research was provided through the 'PCAD4Cod' project granted by the E\&P Sound and Marine Life Joint Industry Programme (JIP). Infrastructure for fieldwork (RV Simon Stevin, RHIB Zeekat and receiver deployment) were provided by Flanders Marine Institute and funded by the Research Foundation-Flanders (FWO) as part of the Belgian contribution to LifeWatch.

\section{Availability of data and materials}

The datasets generated during the current study are available through the European Tracking Network (ETN) repository, http://www.lifewatch.be/etn, upon request. Further information on the analyses used can be obtained from the corresponding author.

\section{Declarations}

\section{Ethics approval and consent to participate}

Catching and tagging treatment of free-ranging animals was performed under the approved ethical certificate number EC2017-080, in line with official guidelines for animal welfare in Flanders.

\section{Consent for publication}

Not applicable.

\section{Competing interests}

The authors declare that they have no competing interests.

\section{Author details \\ ${ }^{1}$ Marine Biology Lab, Ghent University, Krijgslaan 281, 9000 Ghent, Belgium. ${ }^{2}$ Institute of Biology, Leiden University, Sylviusweg 72, 2333 BE Leiden, The Netherlands. ${ }^{3}$ Wageningen Marine Research, Wageningen University \& Research, Haringkade 1, 1976 CP IJmuiden, The Netherlands. ${ }^{4}$ Flanders Marine Institute, Wandelaarkaai 7, 8400 Ostend, Belgium.}

Received: 17 September 2020 Accepted: 10 March 2021 Published online: 09 April 2021

\section{References}

1. Donaldson MR, Hinch SG, Suski CD, Fisk AT, Heupel MR, Cooke SJ. Making connections in aquatic ecosystems with acoustic telemetry monitoring. Front Ecol Environ. 2014;12:565-73. 
2. Hussey NE, Kessel ST, Aarestrup K, Cooke SJ, Cowley PD, Fisk AT, et al. Aquatic animal telemetry: a panoramic window into the underwater world. Science. 2015;348:6240.

3. Gandra M, Erzini K, Abecasis D. Diel and seasonal changes in the spatial behaviour of a soft-sediment fish (Solea senegalensis) inside a marine reserve. Mar Environ Res. 2018;135:82-92.

4. Leclercq E, Zerafa B, Brooker AJ, Davie A, Migaud H. Application of passive-acoustic telemetry to explore the behaviour of ballan wrasse (Labrus bergylta) and lumpfish (Cyclopterus lumpus) in commercial Scottish salmon sea-pens. Aquaculture. 2018;495:1-12.

5. Neo YY, Hubert J, Bolle LJ, Winter HV, Slabbekoorn H. European seabass respond more strongly to noise exposure at night and habituate over repeated trials of sound exposure. Environ Pollut. 2018;239:367-74.

6. Heupel MR, Semmens JM, Hobday AJ. Automated acoustic tracking of aquatic animals: scales, design and deployment of listening station arrays. Mar Freshw Res. 2006:57:1-13.

7. Ellis RD, Flaherty-walia KE, Collins AB, Bickford JW, Boucek R, Walters SL, et al. Acoustic telemetry array evolution : from species- and projectspecific designs to large-scale, multispecies, cooperative networks. Fish Res. 2019;209:186-95.

8. Harrison PM, Gutowsky LFG, Martins EG, Patterson DA, Cooke SJ, Power M. Personality-dependent spatial ecology occurs independently from dispersal in wild burbot (Lota lota). Behav Ecol. 2015;26:483-92.

9. Spiegel O, Leu ST, Bull CM, Sih A. What's your move? Movement as a link between personality and spatial dynamics in animal populations. Ecol Lett. 2017;20:3-18.

10. Steel A, Coates J, Hearn A, Klimley A. Performance of an ultrasonic telemetry positioning system under varied environmental conditions. Anim Biotelemetry. 2014;2:1-17.

11. Kessel ST, Cooke SJ, Heupel MR, Hussey NE, Simpfendorfer CA, Vagle $S$, et al. A review of detection range testing in aquatic passive acoustic telemetry studies. Rev Fish Biol Fish. 2014;24:199-218.

12. Reubens J, Verhelst P, van der Knaap I, Deneudt K, Moens T, Hernandez F. Environmental factors influence the detection probability in acoustic telemetry in a marine environment: results from a new setup. Hydrobiologia. 2019;845:81-94.

13. Espinoza M, Farrugia TJ, Lowe CG. Habitat use, movements and site fidelity of the gray smooth-hound shark (Mustelus californicus Gill 1863) in a newly restored southern California estuary. J Exp Mar Bio Ecol. 2011;401:63-74

14. Biesinger Z, Bolker BM, Marcinek D, Grothues TM, Dobarro JA, Lindberg WJ. Testing an autonomous acoustic telemetry positioning system for fine-scale space use in marine animals. J Exp Mar Bio Ecol. 2013:448:46-56.

15. Swadling DS, Knott NA, Rees MJ, Pederson H, Adams KR, Taylor MD, et al. Seagrass canopies and the performance of acoustic telemetry: implications for the interpretation of fish movements. Anim Biotelemetry. 2020:8:1-12.

16. Huveneers C, Simpfendorfer CA, Kim S, Semmens JM, Hobday AJ, Pederson $\mathrm{H}$, et al. The influence of environmental parameters on the performance and detection range of acoustic receivers. Methods Ecol Evol. 2016;7:825-35.

17. Reubens J, Pasotti F, Degraer S, Vincx M. Residency, site fidelity and habitat use of Atlantic cod (Gadus morhua) at an offshore wind farm using acoustic telemetry. Mar Environ Res. 2013;90:128-35.

18. De Troch M, Reubens JT, Heirman E, Degraer S, Vincx M. Energy profiling of demersal fish: a case-study in wind farm artificial reefs. Mar Environ Res. 2013;92:224-33.

19. Reubens J, De Rijcke M, Degraer S, Vincx M. Diel variation in feeding and movement patterns of juvenile Atlantic cod at offshore wind farms. J Sea Res. 2013;85:214-21.

20. Reubens J, Braeckman U, Vanaverbeke J, Van Colen C, Degraer S, Vincx M. Aggregation at windmill artificial reefs: CPUE of Atlantic cod (Gadus morhua) and pouting (Trisopterus luscus) at different habitats in the Belgian part of the North Sea. Fish Res. 2013;139:28-34.

21. Winter $H$, Aarts $G$, van Keeken $O$. Residence time and behaviour of sole and cod in the Offshore Wind farm Egmond aan Zee (OWEZ). Wageningen UR: IMARES — institute for Marine Resources \& Ecosystem Studies; 2010
22. Righton D, Quayle VA, Hetherington S, Burt G. Movements and distribution of cod (Gadus morhua) in the southern North Sea and English Channel: results from conventional and electronic tagging experiments. J Mar Biol Ass UK. 2007;87:599-613.

23. Righton $\mathrm{D}$, Mills $C M$. Reconstructing the movements of free-ranging demersal fish in the North Sea: a data-matching and simulation method. Mar Biol. 2008;153:507-21.

24. Brabant R, Degraer S, Rumes B. Offshore wind energy development in the Belgian part of the North Sea \& anticipated impacts: an update. Chapter 2: monitoring offshore wind farms in the Belgian part of the North Sea: setting the scene. Brussels: Royal Belgian Institute of Natural Sciences, Management Unit of the North Sea Mathematical Models. Marine Ecosystem Management Unit; 2012. p. 7-15.

25. Degraer S, Brabant R, Rumes B, Vigin L. Environmental impacts of offshore wind farms in the Belgian part of the North Sea: a continued move towards integration and quantification. Brussels: Royal Belgian Institute of Natural Sciences, OD Natural Environment, Marine Ecology and Management Section; 2017.

26. Smith F. Understanding HPE in the VEMCO positioning system (VPS). Availabe: http://vemco.com/wp-content/uploads/2013/09/understand inghpe-vps.pdf. 2013.

27. Meckley TD, Holbrook CM, Wagner CM, Binder TR. An approach for filtering hyperbolically positioned underwater acoustic telemetry data with position precision estimates. Anim Biotelemetry. 2014;2:1-13.

28. Brownscombe JW, Griffin LP, Gagne TO, Haak CR, Cooke SJ, Finn JT, et al. Environmental drivers of habitat use by a marine fish on a heterogeneous and dynamic reef flat. Mar Biol. 2019:166:1-13.

29. Lee KA, Huveneers C, Macdonald T, Harcourt RG. Size isn't everything: movements, home range, and habitat preferences of eastern blue gropers (Achoerodus viridis) demonstrate the efficacy of a small marine reserve. Aquat Conserv Mar Freshw Ecosyst. 2015:25:174-86.

30. La Mesa G, Consalvo I, Annunziatellis A, Canese S. Movement patterns of the parrotfish Sparisoma cretense in a Mediterranean marine protected area. Mar Environ Res. 2012;82:59-68.

31. Worton B. Kernel methods for estimating the utilization distribution in home-range studies. Ecology. 1989;70:164-8.

32. Heupel MR, Simpfendorfer CA, Hueter RE. Estimation of shark home ranges using passive monitoring techniques. Environ Biol Fishes. 2004;71:135-42.

33. Simpfendorfer CA, Olsen EM, Heupel MR, Moland E. Three-dimensional kernel utilization distributions improve estimates of space use in aquatic animals. Can J Fish Aquat Sci. 2012;69:565-72.

34. Duong T. Kernel density estimation and kernel discriminant analysis for multivariate data in R. J Stat Softw. 2015:21:1-16.

35. Espinoza M, Farrugia TJ, Webber DM, Smith F, Lowe CG. Testing a new acoustic telemetry technique to quantify long-term, fine-scale movements of aquatic animals. Fish Res. 2011;108:364-71.

36. Kessel ST, Hussey NE, Webber DM, Gruber SH, Young JM, Smale MJ, et al. Close proximity detection interference with acoustic telemetry: the importance of considering tag power output in low ambient noise environments. Anim Biotelemetry. 2015:3:1-14.

37. Gjelland K, Hedger RD. On the parameterization of acoustic detection probability models. Methods Ecol Evol. 2017:8:1302-4.

38. Özkan Sertlek H, Ainslie MA. A depth-dependent formula for shallow water propagation. J Acoust Soc Am. 2014;136:573-82.

39. Degraer S, Brabant R, Rumes B. Environmental impacts of offshore wind farms in the Belgian part of the North Sea: learning from the past to optimise future monitoring programmes. Bruxelles: Royal Belgian Institute of Natural Sciences Operational Directorate Natural Environment, Marine Ecology and Management Section; 2013.

40. Goossens J, Tjampens M, Deneudt K, Reubens J. Mooring scientific instruments on the seabed-design, deployment protocol and performance of a recoverable frame for acoustic receivers. Methods Ecol Evol. 2020;11:974-9.

41. Fontes J, Schmiing M, Afonso P. Permanent aggregations of a pelagic predator at shallow seamounts. Mar Biol. 2014;161:1349-60.

42. DeCelles GR, Cadrin SX. Movement patterns of winter flounder (Pseudopleuronectes americanus) in the southern Gulf of Maine: observations with the use of passive acoustic telemetry. Fish Bull. 2010;108:408-19. 
43. Melnychuk MC, Dunton KJ, Jordaan A, McKown KA, Frisk MG. Informing conservation strategies for the endangered Atlantic sturgeon using acoustic telemetry and multi-state mark-recapture models. J Appl Ecol. 2017;54:914-25

44. Jacobsen L, Baktoft H, Jepsen N, Aarestrup K, Berg S, Skov C. Effect of boat noise and angling on lake fish behaviour. J Fish Biol. 2014;84:1768-80.

45. Payne NL, van der Meulen DE, Suthers IM, Gray CA, Taylor MD. Foraging intensity of wild mulloway Argyrosomus japonicus decreases with increasing anthropogenic disturbance. Mar Biol. 2014;162:539-46.

\section{Publisher's Note}

Springer Nature remains neutral with regard to jurisdictional claims in published maps and institutional affiliations.
Ready to submit your research? Choose BMC and benefit from:

- fast, convenient online submission

- thorough peer review by experienced researchers in your field

- rapid publication on acceptance

- support for research data, including large and complex data types

- gold Open Access which fosters wider collaboration and increased citations

- maximum visibility for your research: over $100 \mathrm{M}$ website views per year

At BMC, research is always in progress.

Learn more biomedcentral.com/submissions 